\title{
Graphitization of Lignin-Phenol-Formaldehyde Resins
}

\author{
Segun Isaac Talabia ${ }^{a *}$ (1), Ana Paula da Luz ${ }^{a}$, Victor Carlos Pandolfelli ${ }^{a}$,Vitor Hugo Limac, \\ Vagner Roberto Botaroc ${ }^{c}$,Alessandra de Almeida Lucas ${ }^{a}$
}

\author{
${ }^{a}$ Universidade Federal de São Carlos, Departamento de Engenharia de Materiais, Rod. Washington \\ Luiz, km 235, 13565-905, São Carlos, SP, Brasil \\ ${ }^{b}$ University of Ilorin, Materials and Metallurgical Engineering Department, PMB 1515, Ilorin, \\ Kwara State, Nigeria \\ ${ }^{C}$ Universidade Federal de São Carlos, Departamento de Física, Química e Matemática, \\ Rod. João Leme dos Santos, km 110, Itinga, 18052-780, Sorocaba, SP, Brasil
}

Received: December 19, 2019; Revised: March 18, 2020; Accepted: April 10, 2020

\begin{abstract}
Environmental friendliness and cost demand the development of lignin-modified phenolic (LPF) resins for application as a binder for carbon-containing refractories (CCRs) production. Moreover, the in-situ graphitization of such resins can produce crystalline carbon, which is an essential component of CCRs. Consequently, this study investigated LPF resins graphitization using ferrocene, boron oxide and boric acid. The modified resins were synthesized using thermally treated kraft lignin based on 1.5 formaldehyde to phenol molar ratio and with up to $30 \mathrm{wt} \%$ lignin as phenol replacement. The resins chemical composition and the structural organization and oxidation resistance of carbons derived from the plain resins and those containing the graphitizing additives were determined. The results showed that ferrocene and the boron compounds could induce graphitic carbon generation when carbonizing LPF resins at $1500{ }^{\circ} \mathrm{C}$ for 5 hours. The best graphitization level (73\%) was achieved when $10 \mathrm{wt} . \%$ boric acid was added to the resin produced with $20 \mathrm{wt} . \%$ lignin. Regarding the formulations containing ferrocene, the highest amount of graphitic carbon (48\%) was generated when $5 \mathrm{wt} . \%$ of this additive was added to the resin synthesized with $10 \mathrm{wt} . \%$ lignin. The carbons derived from the formulations containing boron oxide presented the best oxidation resistance.
\end{abstract}

Keywords: Kraft lignin, lignin-phenol-formaldehyde resins, synthesis, graphitization.

\section{Introduction}

Phenolic resins offer the advantages of good adhesion, high fixed carbon ratio and high strength on curing and after carbonization, which are necessary to produce carbon-containing refractories. However, fluctuation in oil price and concerns associated with exposure to phenol and formaldehyde during production have led researchers to investigate the use of bio-based materials from renewable resources as a phenol substitute in phenolic resins production ${ }^{1,2}$. Similarly, the need to develop low-cost phenolic resin through the incorporation of abundantly available lignin is gaining increasing attention. Lignin, a by-product of many agro-based processes such as pulp, paper and bioethanol industries can serve as an alternative replacement to phenol in the synthesis of phenolic resin ${ }^{3}$. It is a renewable source with an annual production estimated in the range of 5-36 $\times 10^{8}$ tons $^{4}$. Lignin can exhibit various structures, depending on the vegetal species it is derived from. It is primarily comprised of three repeating units, which are guaiacyl (G-unit), syringyl (S-unit) and p-hydroxyphenyl propane ( $\mathrm{p}-\mathrm{H}$ unit) Consequently, it can be classified as a polyphenolic compound and possesses the ability to react with formaldehyde at the $\mathrm{C}-5$ position of the aromatic ring of guaiacyl structure and at the $\mathrm{C}-\beta$ location of the phenylpropane

*e-mail: talabi.si@unilorin.edu.ng unit ${ }^{5}$. Lignin reactivity depends on the interunit linkages of functional groups such as methoxyl, aldehyde, phenolic and aliphatic hydroxyl ${ }^{6}$. Their chemical structure and characteristics usually depend on the feedstock sources and isolation processes. Although it can be obtained from different pulping processes, only lignosulfonates are available in large commercial quantities. Ammonium lignosulfonates have been reported as the most suitable candidate from the family of lignosulfonates to formulate phenolic resins because of their solubility in organic solvents ${ }^{1,7}$. Nevertheless, they have higher molecular weight values and lower reactivity compared to organosolv and kraft $\operatorname{lignin}^{8-13}$. Therefore, the latter lignin categories (organosolv and kraft) could be more appropriate for ligninphenol-formaldehyde (LPF) resins synthesis. Nevertheless, the feedstock from which lignin is derived plays a more significant role in determining their suitability for phenolic resins production. Generally, softwoods lignin contains a higher amount of G-component unlike the hardwood ones, which comprise $\mathrm{G}$ and S-components. Hydrolysis lignin ${ }^{14-16}$, soda lignin ${ }^{17}$ and biorefinery residue ${ }^{18,19}$ have also been used to produce lignin-modified phenolic resins. The suitable candidates for producing phenolic resins are rich in hydroxyl groups in the aromatic ring, less in methoxyl group and have low molecular weight values ${ }^{20}$. 
The synthesis of lignin-modified phenolic resin has been the subject of various research studies. However, the complete replacement of phenol with lignin is still a subject of on-going research studies due to lignin low reactivity toward formaldehyde. Consequently, research effort has been geared toward increasing its susceptibility to chemical reaction through techniques such as demethylation, phenolation, methylolation and depolymerization ${ }^{1,2,21}$. Methylolation and phenolation introduced reactive functional groups to lignin molecules whereas demethylation modifies lignin to form catechol moieties in lignin macromolecule ${ }^{2}$. In some studies $^{22,23}$, up to $75 \%$ depolymerized lignin have been used to replace phenol during the preparation of phenolic resins. However, such resins may be more suitable for application as adhesive materials. Other techniques such as reduction, selective oxidation of $\beta-O-4$ linkages using nitrobenzene ${ }^{24,25}$, sulfonation ${ }^{26}$ and hydrolysis have also been studied to improve lignin reactivity or produce phenolic compounds from lignin.

LPF resins can be used as a binder (or adhesive) for various engineering applications such as those involving carbon-containing refractories (CCRs) production. The use of lignin-modified phenolic resin in the production of such refractory is beginning to gain attention. Wang et al. ${ }^{27}$ have recently shown that lignin-modified phenolic resin has good potential to be used as a binder for the production of $\mathrm{Al}_{2} \mathrm{O}_{3}-\mathrm{C}$ refractory. The bricks developed with this modified resin possessed improved thermomechanical properties than those with the conventional type. Moreover, the properties of CCRs depend strongly on the features of the carbonaceous phase. Optimum properties are attained if the refractory formulation contains crystalline and not amorphous carbon. Generally, thermosetting resins that are used to bond the brick aggregates together usually yield non-crystalline carbons during sintering. Hence, the in-situ graphitization of these non-graphitizable binders to generate additional graphitic carbon during the heat treatment operation has been considered as a means of improving the refractory composite properties ${ }^{28,29}$. The crystallization of this material has been shown to enhanced their (CCRs) thermomechanical performance ${ }^{30,31}$. However, based on the literature considered in this present work, the catalytic graphitization of carbons derived from LPF resins has not been investigated. This aspect is one of the novelties of the present investigation as it provides information about graphitic carbon generation from low-cost polymers.

The environmental friendliness and high cost associated with the use of phenolic resins for CCRs production has also been considered. As the most abundant natural aromatic polymer in the world, the use of lignin is cost-effective and has better environment-friendliness. Hence, the choice of LPF resins and the graphitization of their carbons can address the aforementioned challenges. Moreover, its usage (as renewable biomass) in the development of LPF resins will promote sustainable technology development.

Consequently, this study examined the influence of some additives on the generation of graphitic carbons from ligninmodified phenolic resin. The employed pyrolysis procedure can be used to produce refractory bricks. Up to $30 \mathrm{wt} . \% \mathrm{kraft}$ lignin, which has been demonstrated as a suitable binder for $\mathrm{CCRs}^{27}$ was used in the present study to prepare lignin-modified phenolic resins. The benefits of in-situ graphitization of the binder component on the CCRs' thermomechanical properties will be determined in a future study.

\section{Experimental Techniques}

\subsection{Raw materials}

The general information regarding the raw materials used in this study and samples designation is shown in Table 1. The reagents were used as received, except the kraft lignin

Table 1. General information about the used materials and samples designation

\begin{tabular}{ccc}
\hline Raw materials & Supplier \\
\hline Commercial resole resin (Rs, Prefere 88 5000R) & Dynea (Brazil) \\
\cline { 2 - 3 }
\end{tabular}

Binder

Laboratory synthesized resins (10LPF, 20LPF, 30LPF) based on:

-Phenol, $\mathrm{C}_{6} \mathrm{H}_{5} \mathrm{OH}$, solid, molecular weight $=94.11 \mathrm{~g} / \mathrm{mol}$

-Formaldehyde (37 wt. $\%$ ), $\mathrm{CH}_{2} \mathrm{O}$, liquid, molecular weight $=30.03 \mathrm{~g} / \mathrm{mol}$

-Kraft Lignin, $\mathrm{pH}=4.5$ at $28^{\circ} \mathrm{C}$

Synth Chemical Co.,

SP-Brazil

Fibria, Brazil

\begin{tabular}{|c|c|c|}
\hline Catalyst & $\mathrm{NH}_{4} \mathrm{OH}$, aqueous, molecular weight $=35.04 \mathrm{~g} / \mathrm{mol}$ & $\begin{array}{l}\text { Synth Chemical Co., } \\
\text { SP-Brazil }\end{array}$ \\
\hline \multirow{3}{*}{ Additives } & Ferrocene $(150<\mathrm{d}<70 \mu \mathrm{m}, 98 \%$ purity $)$ & Aldrich, USA \\
\hline & $\begin{array}{l}\text { Boric acid }\left(\mathrm{H}_{3} \mathrm{BO}_{3}\right) \text {, solid powder, molecular weight }=61.83 \mathrm{~g} / \mathrm{mol}, \\
\left(\mathrm{d}_{90}<45 \mu \mathrm{m}, 99 \% \text { purity }\right)\end{array}$ & $\begin{array}{l}\text { Synth Chemical Co., } \\
\text { SP-Brazil }\end{array}$ \\
\hline & Boron oxide $\left(\mathrm{B}_{2} \mathrm{O}_{3}\right)$, solid powder, $\left(\mathrm{d}_{50}<10 \mu \mathrm{m}, 99 \%\right.$ purity $)$ & $\begin{array}{l}\text { RHI-Magnesita } \\
\text { refractories, Brazil }\end{array}$ \\
\hline Samples Designation & \multicolumn{2}{|c|}{ Description } \\
\hline 10LPF, 20LPF, 30LPF & \multicolumn{2}{|c|}{$\begin{array}{l}\text { Lignin-phenol-formaldehyde resin synthesized with } 10 \mathrm{wt} . \%, 20 \mathrm{wt} . \%, 30 \mathrm{wt} . \% \text { of lignin as a substitute for } \\
\text { phenol, respectively. }\end{array}$} \\
\hline $1.5 \mathrm{Rs}$ & \multicolumn{2}{|c|}{ Laboratory synthesized resole based on formaldehyde to phenol molar ratio $=1.5$} \\
\hline Rs & \multicolumn{2}{|c|}{ Commercial resole resin } \\
\hline $3 \mathrm{Fc}$ & \multicolumn{2}{|l|}{3 wt. $\%$ Ferrocene } \\
\hline $10 \mathrm{H}$ & \multicolumn{2}{|l|}{10 wt. $\%$ Boric acid $\left(\mathrm{H}_{3} \mathrm{BO}_{3}\right)$} \\
\hline $6 \mathrm{~B}$ & \multicolumn{2}{|l|}{6 wt. $\%$ Boron oxide $\left(\mathrm{B}_{2} \mathrm{O}_{3}\right)$} \\
\hline
\end{tabular}


that was subjected to further processing. Boron oxide, boric acid and ferrocene additives were used as graphitizing agents for the lignin-modified phenolic resins. The boron source compounds were investigated to find a cheaper and good alternative material to ferrocene that can promote crystalline carbon generation during the resins' carbonization.

\subsection{Thermal treatment and characterization of kraft lignin}

Before synthesis, the kraft lignin was subjected to thermal treatment at $200{ }^{\circ} \mathrm{C}$ at $3{ }^{\circ} \mathrm{C} / \mathrm{min}$ inside a muffle furnace for one hour under a non-oxidizing atmosphere to improve lignin reactivity. The obtained material was ground with a glass mortar and pestle into a powder form that was used for the LPF resins production.

The glass transition temperature $\left(\mathrm{T}_{\mathrm{g}}\right)$ of the as-received and heat-treated samples was determined using DSCQ2000, TA Instruments. For this measurement, about 6-7 mg of each sample was enclosed in an aluminium pan. The analysis was conducted in a nitrogen atmosphere at $10{ }^{\circ} \mathrm{C} / \mathrm{min}$ and a flow rate of $10 \mathrm{~mL} / \mathrm{min}$. The samples were heated from ambient temperature to $105^{\circ} \mathrm{C}$ and kept at that temperature for 5 minutes before cooling to $-60{ }^{\circ} \mathrm{C}$ and a holding time of 2 minutes to eliminate the presence of water. After that, the samples were heated to $200{ }^{\circ} \mathrm{C}$ at $10{ }^{\circ} \mathrm{C} / \mathrm{min}$ to determine the $\mathrm{T}_{\mathrm{g}}$, which was defined as the inflection point (mid-point) on the DSC curve, according to ASTM E 1356-08.

The effect of heat treatment on the as-received kraft lignin molecular weight distribution was determined. Regarding the measurement, $100 \mathrm{mg}$ of each sample was weighed and dissolved in $2 \mathrm{ml}$ of pyridine solution and acetic anhydride (1: $1 \mathrm{v} / \mathrm{v}$ ) at $105{ }^{\circ} \mathrm{C}$ for 2 hours. The acetylated material was precipitated in $30 \mathrm{ml}$ of distilled water and centrifuged at $7500 \mathrm{rpm}$ for 15 minutes. Thereafter, the samples were dissolved in tetrahydrofuran (THF) in a 1:100 mass ratio and analyzed by an Agilent Technologies 1260 Infinity II GPC equipment. The chromatographic run was done at 12 minutes permeation time, $1 \mathrm{ml} / \mathrm{min}$ solvent flow, $30{ }^{\circ} \mathrm{C}$ column temperature, $40^{\circ} \mathrm{C}$ sensor temperature and $5-20$ bar pressure.

Moreover, the $\mathrm{pH}$ of both materials was determined using W3B GEL $\mathrm{pH}$ meter after soaking $1 \mathrm{~g}$ of each sample in $25 \mathrm{ml}$ distilled water for 30 minutes.

\subsection{FTIR-ATR measurement of lignin and the synthesized resins}

The as-received and thermally treated lignin samples, as well as the resins, were analyzed using Fourier Transform Infrared-Attenuated Total Reflectance (FTIR-ATR) spectroscopy, model: Nicolet 6700. The measurements were obtained at a wavenumber range of $400-4000 \mathrm{~cm}^{-1}$ and 32 accumulations at $2 \mathrm{~cm}^{-1}$ resolution.

\subsection{Synthesis and carbonization of lignin-phenol-formaldehyde resins}

Lignin-phenol-formaldehyde (LPF) resole resins were synthesized based on 1.5 formaldehyde to phenol molar ratio using thermally treated kraft lignin. The primary monomer reactants ratio was based on the results attained in a previous study regarding the graphitization of conventional resole resins $^{32}$. In that study, the resin prepared based on this molar ratio generates the highest amount of graphitic carbon after carbonization. The modified resins were produced according to the following procedure. Firstly, the solution mixture of phenol, water and $\mathrm{NH}_{4} \mathrm{OH}$ (catalyst) was heated up to $65 \pm 5^{\circ} \mathrm{C}$ with a hot-plate magnetic stirrer via an oil bath for 30 minutes inside a glassware set-up. The amount of phenol used depends on the intended lignin to phenol weight percentage ratio. This reaction step was catalyzed by $70 \%$ ( $8.6 \mathrm{wt} . \%$ of phenol quantity) of the total amount of the catalyst. After that, the required quantity of the heat-treated kraft lignin was added slowly to the mixture. The reaction was allowed to continue for another 30 minutes before adding the remaining $\mathrm{NH}_{4} \mathrm{OH}$ (3.7 wt.\% of phenol quantity) and formaldehyde (37 wt.\%). The synthesis then proceeded to completion at a maximum temperature of $75 \pm 5^{\circ} \mathrm{C}$. The amount of lignin used for the preparation represents $10 \mathrm{wt} . \%$ (10LPF), $20 \mathrm{wt} . \%$ (20LPF) and $30 \mathrm{wt} . \%$ (30LPF) of phenol, respectively.

Before carbonization, the lignin-modified resoles and the graphitizing agents (3-5 wt.\% ferrocene, $6 \mathrm{wt} . \%$ boron oxide and $10 \mathrm{wt} . \%$ boric acid) were mixed with the aid of a mechanical mixer (Etica Scientific Equipment, Model: 105, No.: 0209) to disperse the additives within the resin. The mixing was carried out at a rotation speed of $300 \mathrm{rpm}$ for ten minutes at room temperature. Each of the additives was mixed separately to prepare mixtures containing either boron oxide, boric acid or ferrocene. The obtained formulations were poured into aluminium crucibles, covered with lids and buried inside a refractory box containing coke. The heat treatment was done using a stepwise heating procedure, which involved carbonizing the samples from $30{ }^{\circ} \mathrm{C}$ to $100{ }^{\circ} \mathrm{C}$ and keeping it at that temperature for 4 hours, followed by increasing the temperature to $500{ }^{\circ} \mathrm{C}$ and holding it there for 1 hour and finally raising it to $1000^{\circ} \mathrm{C}$ and $1500{ }^{\circ} \mathrm{C}$ for 5 hours, respectively ${ }^{28}$. The pyrolysis was carried out inside an electrical furnace at $3{ }^{\circ} \mathrm{C} / \mathrm{min}$ heating rate.

\section{$2.5 X R D$ analysis of the derived carbon samples}

The carbon materials derived from the carbonized resins formulations were initially ground inside a glassware mortar. Thereafter, the prepared samples were characterized with X-ray diffraction (XRD) equipment for phase identification, graphitization level (GL) determination and to obtain structural information such as interlayer spacing $\left(\mathrm{d}_{002}\right)$, crystallite height $\left(\mathrm{L}_{\mathrm{c}}\right)$ and crystallite size $\left(\mathrm{L}_{\mathrm{a}}\right)$. The analysis was done using Shimadzu X-ray diffraction equipment (LabX XRD-6000) under $\mathrm{CuK} \alpha$ radiation $\left(\lambda=1.5418 \AA\right.$, scanning step $\left.=0.0196^{\circ}\right)$. Phase identification was carried out with the help of Search-match software and OriginPro 9 was used for peaks deconvolution as reported by Bitencourt et al. ${ }^{29}$ and Talabi et al. ${ }^{28}$. The GL value of each carbon samples was calculated using Equation 1. Regarding this calculation, the total area related to graphitic carbons peaks was divided by the sum of those associated with graphitic and non-graphitic carbons. Non-carbon peaks were not considered for the calculation. Equation 2 and 3 were used to obtain the $\mathrm{d}_{002}, \mathrm{~L}_{\mathrm{c}}$ and $\mathrm{L}_{\mathrm{a}}$ values. 


$$
\begin{gathered}
\mathrm{GL}=\frac{\text { Graphitic carbon area }}{\text { Total area }(\text { graphitic carbon }+ \text { non }- \text { graphitic carbon })} \\
\mathrm{n} \lambda=\mathrm{d}_{200} 2 \sin \theta \\
\mathrm{k} \lambda=\mathrm{L}_{\mathrm{c}} \beta \cos \theta
\end{gathered}
$$

where $\mathrm{n}=$ positive integer, $\mathrm{d}_{200}(\mathrm{~nm})=$ interlayer spacing, $\theta=$ incident angle, $\mathrm{L}_{\mathrm{c}}(\mathrm{nm})=$ crystallite height, $\mathrm{L}_{\mathrm{a}}=$ crystallite size and $\mathrm{k}=0.89$ for $\mathrm{L}_{\mathrm{c}}$ or 1.84 for $\mathrm{L}_{\mathrm{a}}$.

\subsection{Microstructural analysis}

The carbon samples microstructure was studied with FEI Tecnai G2 F20 transmission electron microscope (TEM) at $200 \mathrm{kV}$. The analysis provided information about TEM images, lattice resolution imaging (HRTEM) and Selected Area Electron Diffraction (SAED) patterns of the graphitized carbons derived from the carbonized resin formulations. The images and SAED patterns were analyzed with GATAN DigitalMicrograph software (Gatan, Inc., USA) to determine parameters such as interplanar spacing.

\subsection{Thermogravimetric analysis}

A NETZSCH STA 449F3 (Netzsch Inc., Germany)-type analyzer was used to determine the oxidation resistance of carbons obtained after the resins (with and without the various graphitizing additives) pyrolysis. The apparatus detects mass loss with a resolution of $0.001 \mathrm{~g}$ as a function of temperature and time and heat flow with $0.0001 \mathrm{~mW} / \mathrm{mg}$ resolution. Before the measurement, the ground sample was evenly distributed in an alumina sample pan. The analysis was carried out in an oxidizing environment (with synthetic air $\left(80 \% \mathrm{~N}_{2}, 20 \% \mathrm{O}_{2}\right)$ at $50 \mathrm{~cm}^{3} / \mathrm{min}$ flow rate) starting from $30^{\circ} \mathrm{C}$ to $1000{ }^{\circ} \mathrm{C} \pm 10^{\circ} \mathrm{C}$ at a heating rate of $10^{\circ} \mathrm{C} / \mathrm{min}$. The carbon loss and oxidation initiation temperature of the samples were extracted from the non-isothermal TGA curve. The thermogravimetric (TG) curves were normalized to eliminate the effect of non-carbon material described by the initial mass loss between $30^{\circ} \mathrm{C}$ to $\sim 150{ }^{\circ} \mathrm{C}$. The normalizing procedure ${ }^{32,33}$ helps to determine the actual carbon loss from the inflexion point representing the onset of oxidation $\left(T_{i}\right)$.

\section{Results and Discussion}

\subsection{Characterization of the as-received and heat-treated lignin}

Figure 1 shows the spectra in the wavenumber range from 400 to $4000 \mathrm{~cm}^{-1}$ of the as-received kraft lignin and the one heat-treated at $200{ }^{\circ} \mathrm{C}$ for 1 hour, which was done to enhance lignin reactivity during the synthesis reactions. The spectra of both the untreated and treated samples were characterized with peaks at $650 \mathrm{~cm}^{-1}, 821 \mathrm{~cm}^{-1}$, and $912 \mathrm{~cm}^{-1}$, which correspond to $\mathrm{C}-\mathrm{H}$ vibration bonds of benzene rings. The one at $1030 \mathrm{~cm}^{-1}$ matches with $\mathrm{C}-\mathrm{O}$ bonds stretching vibration caused by alcoholic ether groups. This peak may be explicitly assigned to the aliphatic $\mathrm{C}-\mathrm{O}(\mathrm{Ar})$, aliphatic $\mathrm{C}-\mathrm{OH}$, and methylol $\mathrm{C}-\mathrm{OH}$ in the syringyl unit of lignin ${ }^{34}$. The peak at $1110 \mathrm{~cm}^{-1}$ belongs to the stretching vibration of the $\mathrm{C}-\mathrm{O}$ bonds from ether linkages adsorption. Phenolic hydroxyl groups vibration of the lignin polymer structure belonging to guaiacyl and syringyl groups correspond to the peaks at $1211 \mathrm{~cm}^{-1}$ and $1325 \mathrm{~cm}^{-1}$, respectively ${ }^{35,36}$. Consequently, these profiles showed that the samples are rich in guaiacyl unit, making them suitable for phenolic resin production. The peaks at $1456 \mathrm{~cm}^{-1}$ and the ones at $1519 \mathrm{~cm}^{-1}$ and $1600 \mathrm{~cm}^{-1}$ belong to $-\mathrm{OCH}_{3}$ in acetyl groups and $\mathrm{C}=\mathrm{C}$ vibrations of the aromatic ring, respectively. The $\mathrm{CH}$ stretching vibration of the methoxyl group was observed at $2833 \mathrm{~cm}^{-1}$ and $2933 \mathrm{~cm}^{-136}$. The band at $3460 \mathrm{~cm}^{-1}$ was ascribed to $\mathrm{OH}$ vibrations due to the alcoholic and phenolic hydroxyl groups. The units containing the free phenolic hydroxy groups are more susceptible to cleavage. No new functional group was detected after heating the lignin sample up to $200^{\circ} \mathrm{C}$. However, the peak intensity assigned to ether linkages at $1110 \mathrm{~cm}^{-1}$ reduced due to ether bonds cleavage. Although some studies have attributed this peak to aromatic in-plane $\mathrm{CH}$ vibration ${ }^{37,38}$, other authors have suggested that it may be due to ether-type linkages ${ }^{39-41}$ or a combination of both contributions ${ }^{42}$. However, the ease of synthesis, which was observed during the resin production (compared to when the as-received kraft lignin was used during the initial experimental stages) attests that the peak is more likely due to ether linkages. The cracking of ether bonds has been observed to occur within the temperature range of $200{ }^{\circ} \mathrm{C}$ to $400{ }^{\circ} \mathrm{C}$ depending on the presence of phenolic $(\mathrm{Ph})$ and non-phenolic (Non-Ph) dimers ${ }^{43,44}$. The heterolysis cleavage of $\alpha$-ether bond in $\mathrm{Ph}$ compounds can form quinone methide intermediate which can result in a simultaneous homolytic cleavage of the $\beta$-ether bond at $200{ }^{\circ} \mathrm{C}^{44}$. The observation was also consistent with the results obtained by Nakamura et $\mathrm{al}^{45}$.

Furthermore, there was no evidence of demethylation reaction, as the cleavage of $\mathrm{O}-\mathrm{CH}_{3}$ bond should produce a new $\mathrm{OH}$ group (as a result of the replacement of $\mathrm{CH}_{3}$ by hydrogen) which will lead to increased intensity of the band between $3200 \mathrm{~cm}^{-1}$ and $3650 \mathrm{~cm}^{-1}{ }^{46}$ Instead, the band intensity slightly decreased. Also, the peak intensities at $1456 \mathrm{~cm}^{-1}$, $2839 \mathrm{~cm}^{-1}$ and $2936 \mathrm{~cm}^{-1}$ that were attributed to methoxyl group also remain the same, confirming this assertion ${ }^{39}$. Consequently, the observed ease of synthesis which allows the lignin modified phenolic resins preparation was mainly due to ether cleavage. The peaks corresponding to phenolic

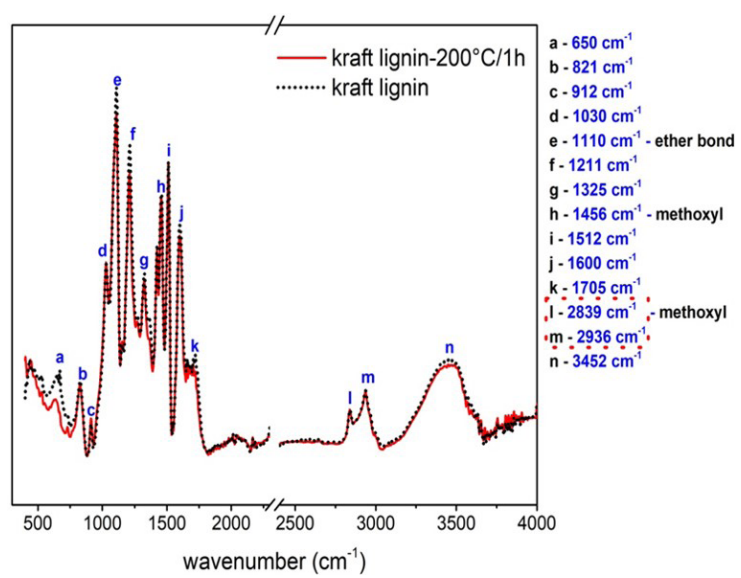

Figure 1. FTIR-ATR analysis of as-received and heat-treated kraft lignin samples. 
hydroxyl groups' vibration of the guaiacyl and syringyl unit also decreased at the higher temperature $\left(200{ }^{\circ} \mathrm{C}\right)$. This reduction may be ascribed to the decomposition of the phenolic groups ${ }^{42}$. Generally, lignin that is suitable for LPF development should be rich in $\mathrm{OH}$ group. However, the decrease in the intensities of peaks corresponding to - $\mathrm{OH}$ group has no pronounced effect on the resins' production because the employed synthesis sequence promoted phenolation reaction.

Finally, the peak intensity attributed to the $\mathrm{C}-\mathrm{H}$ vibration bond at $912 \mathrm{~cm}^{-1}$ reduced due to dehydration reaction at $200{ }^{\circ} \mathrm{C}^{42}$. Also, the one assigned to $\mathrm{C}-\mathrm{H}$ vibration of the benzene ring decreased and shifted to $635 \mathrm{~cm}^{-1}$, which may likely be due to hemicelluloses impurities decomposition ${ }^{43}$.

The average molecular weights and polydispersivity (PD) of the as-received and thermally treated kraft lignin were determined using GPC technique and the results are presented in Table 2. The average molecular weight by number $\left(M_{n}\right)$ and weight $\left(\mathrm{M}_{\mathrm{w}}\right)$ values of the sample significantly reduce after heat treatment at $200{ }^{\circ} \mathrm{C}$ for 1 hour. Compared to the as-received material ( $\mathrm{Mw}=3064 \mathrm{~g} / \mathrm{mol}$ and $\mathrm{Mn}=707 \mathrm{~g} / \mathrm{mol})$, the heat-treated lignin has $\mathrm{M}_{\mathrm{w}}$ and $\mathrm{M}_{\mathrm{n}}$ values of $1957 \mathrm{~g} / \mathrm{mol}$ and $539 \mathrm{~g} / \mathrm{mol}$, respectively. It is apparent that degradation reaction most likely occurs during the heating process and produced lower molecular weight lignin with more reactive sites. In-line with the FTIR results, ether bond cracking, which is the most dominant bond of the total linkages in lignin should be responsible for the depolymerization reaction.

Figure 2 shows the overlaid molecular weight distributions of the as-received and thermally treated kraft lignin. The former sample has a broader distribution compared to the latter due to the degradation reaction. The as-received lignin PD value decreases from 4.33 to 3.63 after the heat treatment process (Table 2). The attained results agree with the information obtained from the FTIR analysis, which shows lignin degradation after the thermal treatment.

The thermal degradation of the as-received kraft lignin did not result in any significant effect on the glass transition temperature. The $\mathrm{T}_{\mathrm{g}}$ values of the as-received sample and the one subjected to thermal treatment at $200{ }^{\circ} \mathrm{C}$ were determined to be $129.4{ }^{\circ} \mathrm{C}$ and $130.2^{\circ} \mathrm{C}$, respectively. These values are within the range of those that have been previously used for lignin-modified phenolic resins production ${ }^{47,48}$. However, at $28^{\circ} \mathrm{C}$, the $\mathrm{pH}$ of the heat-treated sample was 5.2 compared to 4.5 of the as-received material and the former was also more miscible in water.

\subsection{FTIR-ATR analysis of the lignin-phenol- formaldehyde resins}

Figure 3 shows the lignin-phenol-formaldehyde resins, equivalent unmodified-laboratory synthesized resole (molar ratio $=1.5$ ) and a commercial resole product FTIR spectra. As expected, some slight peaks shift (regarding highlighted peaks of the 30LPF spectrum in Figure 3) was observed between each of the different resins. Regarding the conventional resole resins (commercial and laboratory synthesized ones), the absorption band at 3375 to $3410 \mathrm{~cm}^{-1}$ range corresponds to $\mathrm{OH}$ stretch of the phenolic hydroxyl group. Some minor peaks were detected at $2870 \mathrm{~cm}^{-1}$ and $\sim 2940 \mathrm{~cm}^{-1}$ and were attributed to out of phase and in-phase stretching vibration of $-\mathrm{CH}_{2}$ group, respectively. The peaks at $\sim 1455 \mathrm{~cm}^{-1}$ and $\sim 1592 \mathrm{~cm}^{-1}$ correspond to $\mathrm{C}=\mathrm{C}$ vibrations of the aromatic ring. The wavenumber at $\sim 1374 \mathrm{~cm}^{-1}$ may be due to $\mathrm{OH}$ in-plane bond or $\mathrm{C}-\mathrm{H}$ vibrations ${ }^{49}$. Also, the symmetric stretch of phenolic C-C-OH was responsible for the one at $1226 \mathrm{~cm}^{-149}$. The peaks at $\sim 1020 \mathrm{~cm}^{-1}$ and $\sim 1111 \mathrm{~cm}^{-1}$ were attributed to aliphatic hydroxyl group and the asymmetric stretching vibration of C-O-C aliphatic ether, respectively ${ }^{47}$. The region below $\sim 900 \mathrm{~cm}^{-1}$ was characterized by $\mathrm{CH}$ deformation of aromatic rings. The peak at $\sim 824 \mathrm{~cm}^{-1}$ and $\sim 754 \mathrm{~cm}^{-1}$ correspond to out-of-plane, para-substituted and ortho-substituted $\mathrm{CH}$ positions, respectively ${ }^{49}$. The intensities of these two peaks suggested a high proportion of ortho-linkages (but lower compared to the LPF resins) in both the commercial and

Table 2. The average molecular weight and polydispersity index $\left(\mathrm{M}_{\mathrm{w}} / \mathrm{M}_{\mathrm{n}}\right)$ values of the as-received and thermally treated kraft lignin.

\begin{tabular}{lccc}
\hline \multicolumn{1}{c}{ Lignin samples } & $\mathrm{M}_{\mathrm{w}}(\mathrm{g} / \mathrm{mol})$ & $\mathrm{M}_{\mathrm{n}}(\mathrm{g} / \mathrm{mol})$ & $\mathrm{PD}\left(\mathrm{M}_{\mathrm{w}} / \mathrm{M}_{\mathrm{n}}\right)$ \\
\hline As-received & 3064 & 707 & 4.33 \\
\hline Thermally treated & 1957 & 539 & 3.63 \\
\hline
\end{tabular}

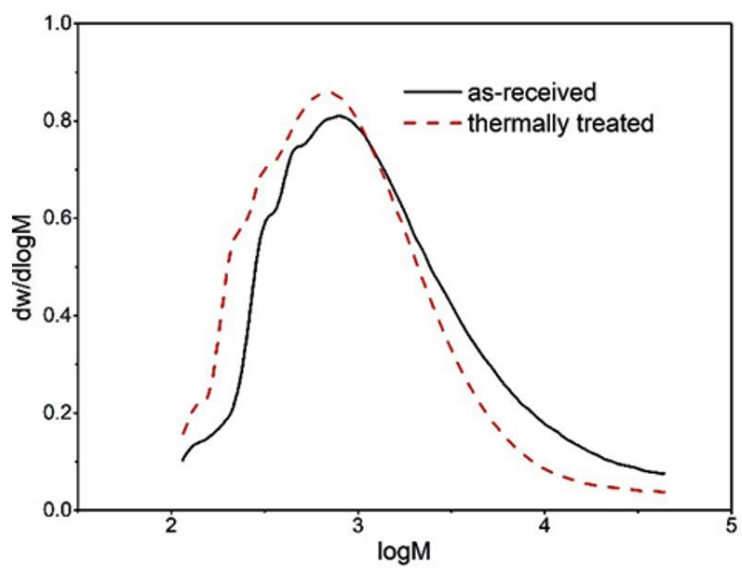

Figure 2. As-received and thermally treated kraft lignin overlaid molecular weight distributions from GPC measurements.

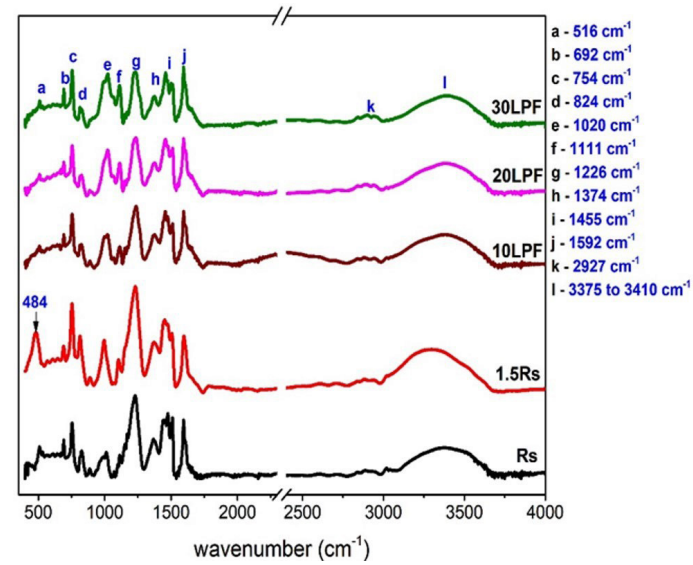

Figure 3. FTIR spectra of lignin-phenol-formaldehyde resins, equivalent unmodified resin and commercial resole product. $\mathrm{Rs}=$ commercial resole, 10LPF, 20LPF, 30LPF $=10-30 \mathrm{wt} . \%$ lignin modified phenolic resins, $1.5 \mathrm{Rs}=$ equivalent conventional resole based on 1.5 formaldehyde to phenol molar ratio. 
laboratory synthesized resole products. Furthermore, peaks were detected at $\sim 692 \mathrm{~cm}^{-1}$, which can be linked to $\mathrm{C}-\mathrm{H}$ deformation outside the plane of phenol mono-substituted aromatic rings ${ }^{47}$.

The LPF resoles spectra look like the conventional ones. The similarity of both the conventional and lignin-modified resins spectra suggests that lignin can be used as phenol substitute for resoles production. Nevertheless, some of their peaks were assigned differently based on the primary reactants' monomer. The broad band at $3410 \mathrm{~cm}^{-1}$ is due to $\mathrm{OH}$ stretching vibrations of the alcoholic and phenolic hydroxyl groups in hydrogen bonds ${ }^{36}$. The peaks at $\sim 2927 \mathrm{~cm}^{-1}$ for the LPF resins are due to $\mathrm{CH}$ stretching vibration of the methoxyl group ${ }^{36}$. Phenolic hydroxyl group vibration of the guaiacyl unit corresponds to the one at $\sim 1226 \mathrm{~cm}^{-135,36}$.

Moreover, the peak intensity corresponding to the asymmetric stretching of aliphatic ether increased directly with the weight percentage of lignin used for the synthesis. Similarly, the ortho-substituted links increased proportionally with the amount of lignin used (Table 3). This suggested that the ease of graphitization of the resulting carbons may decrease with an increase in the amount of substituted phenol by lignin because of the higher cross-linking density. This observation agrees with the results obtained regarding the use of ferrocene as a graphitizing agent in the present study. However, this trend did not apply to the boron compounds containing formulations. The observed difference may likely be due to the reactions that occur during the carbonization operation. Unlike ferrocene (which probably acted at high temperatures), boron compounds can participate in the resin cross-linking reactions $\mathrm{s}^{33,50}$. By implication, the resin primary structure will play a significant role in the catalytic graphitization of lignin modified phenolic resins by ferrocene, keeping other factors constant.

\subsection{Characteristics of carbons derived from lignin-phenol-formaldehyde resins without and with $\mathrm{B}_{2} \mathrm{O}_{3}, \mathrm{H}_{3} \mathrm{BO}_{3}$ or ferrocene}

The XRD profiles of the plain LPF carbons are characterized with high-intensity peaks (compare to the conventional resole resin carbons) with a broad hump at $\sim 24^{\circ}$ and $\sim 43^{\circ}$ (Figure $4 \mathrm{a}$ ). This observation suggests that the samples' atoms organization may be slightly better than the conventional one, which might be due to the resin chemistry (Figure 4). Nevertheless, these profiles still present the features of non-graphitic carbons with a limited ordered atomic arrangement. The calculated interlayer spacing and crystallite height values (Table 4) are within the range obtained for amorphous carbons in previous studies ${ }^{28}$. Consequently, there is a need to induce graphitic carbon generation to enhance the thermomechanical performance of resin-bonded CCR bricks.

Boron oxide (6 wt.\%) and boric acid (10 wt.\%) were used as agents to induce crystalline carbon generation during carbonization of lignin-phenol-formaldehyde resins (the amount these additives was based on previous work ${ }^{28}$. Figure 5 shows the diffractograms of the carbons derived from the boron compound-modified resin formulations after subjecting them to a stepwise heat treatment procedure up to $1000{ }^{\circ} \mathrm{C}$ and $1500{ }^{\circ} \mathrm{C}$. At $1000{ }^{\circ} \mathrm{C}$, the obtained patterns depict disordered atoms arrangement. The profiles were characterized with a low-intensity hump across $\sim 24^{\circ}$ (close to 002 plane of graphitic structure) and at $\sim 43^{\circ}$ (100 in-plane symmetry), corresponding to turbostratic graphitic structure (Figures $5 \mathrm{a}$ and $5 \mathrm{~b}$ ). At that temperature, the available energy was not enough to induce crystalline carbon generation during the pyrolysis operation. Consequently, the samples were further heated at $1500^{\circ} \mathrm{C}$ for 5 hours. At this

Table 3. Proportion of ortho and para-substituted linkages

\begin{tabular}{lcccccc}
\hline \multicolumn{1}{c}{ Peaks position $\left(\mathrm{cm}^{-1}\right)$} & Rs & 1.5Rs & 10LPF & 20LPF \\
\cline { 2 - 7 } & & \multicolumn{4}{c}{ Absorbance } \\
\hline 754 (para-substituted CH-position) & 0.19011 & 0.28527 & 0.1685 & 0.14971 \\
\hline 824 (ortho-substituted CH-position) & 0.09996 & 0.18064 & 0.07283 & 0.06273 & 0.05674 \\
\hline Para links proportion (\%) & 34 & 39 & 30.2 & 29.5 \\
\hline
\end{tabular}

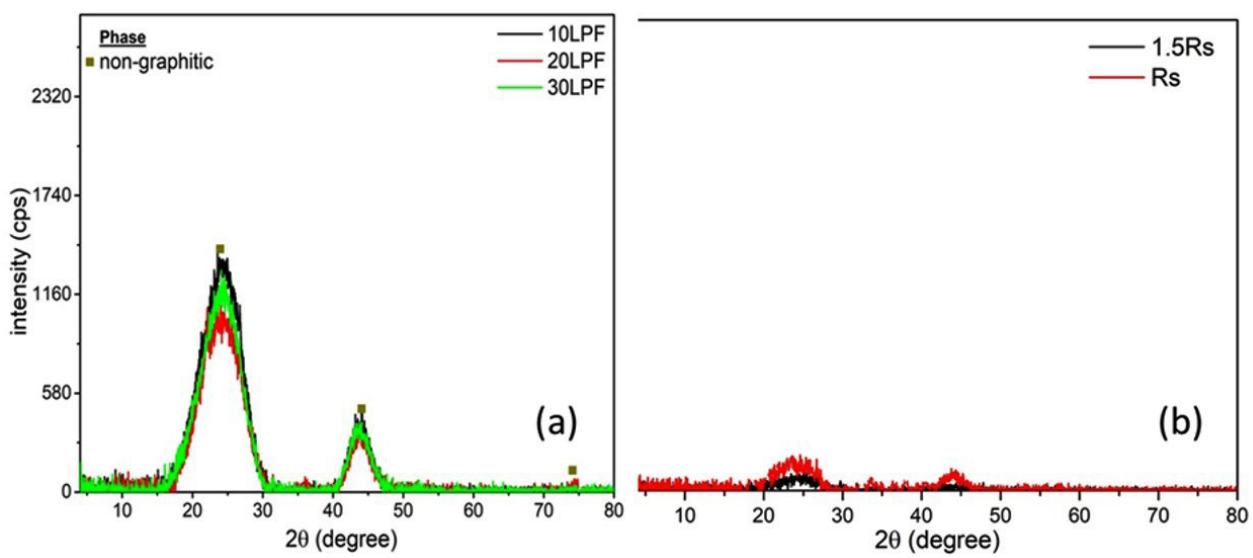

Figure 4. Diffractograms of lignin-phenol-formaldehyde resins carbons after pyrolysis at $1000^{\circ} \mathrm{C} / 5 \mathrm{~h}$. LPF $=$ lignin-phenol-formaldehyde resin, $1.5 \mathrm{Rs}=$ laboratory synthesized resole based on 1.5 formaldehyde to phenol molar ratio, Rs $=$ commercial resole resin. 
Table 4. Interlayer spacing, and crystallite height values of carbon derived from plain LPF resins after thermal treatment at $1000{ }^{\circ} \mathrm{C}$ for $5 \mathrm{~h}$ under reducing environment.

\begin{tabular}{cccc}
\hline Samples & $\mathrm{d}_{002}(\mathrm{~nm})$ & $\mathrm{L}_{\mathrm{c}(002)}(\mathrm{nm})$ & GL $(\%)$ \\
\hline $10 \mathrm{LPF}$ & 0.3690 & 1.19 & $\mathrm{NS}$ \\
\hline $20 \mathrm{LPF}$ & 0.3700 & 1.17 & $\mathrm{NS}$ \\
\hline $30 \mathrm{LPF}$ & 0.3701 & 1.19 & NS \\
\hline
\end{tabular}

*NS $=$ not significant
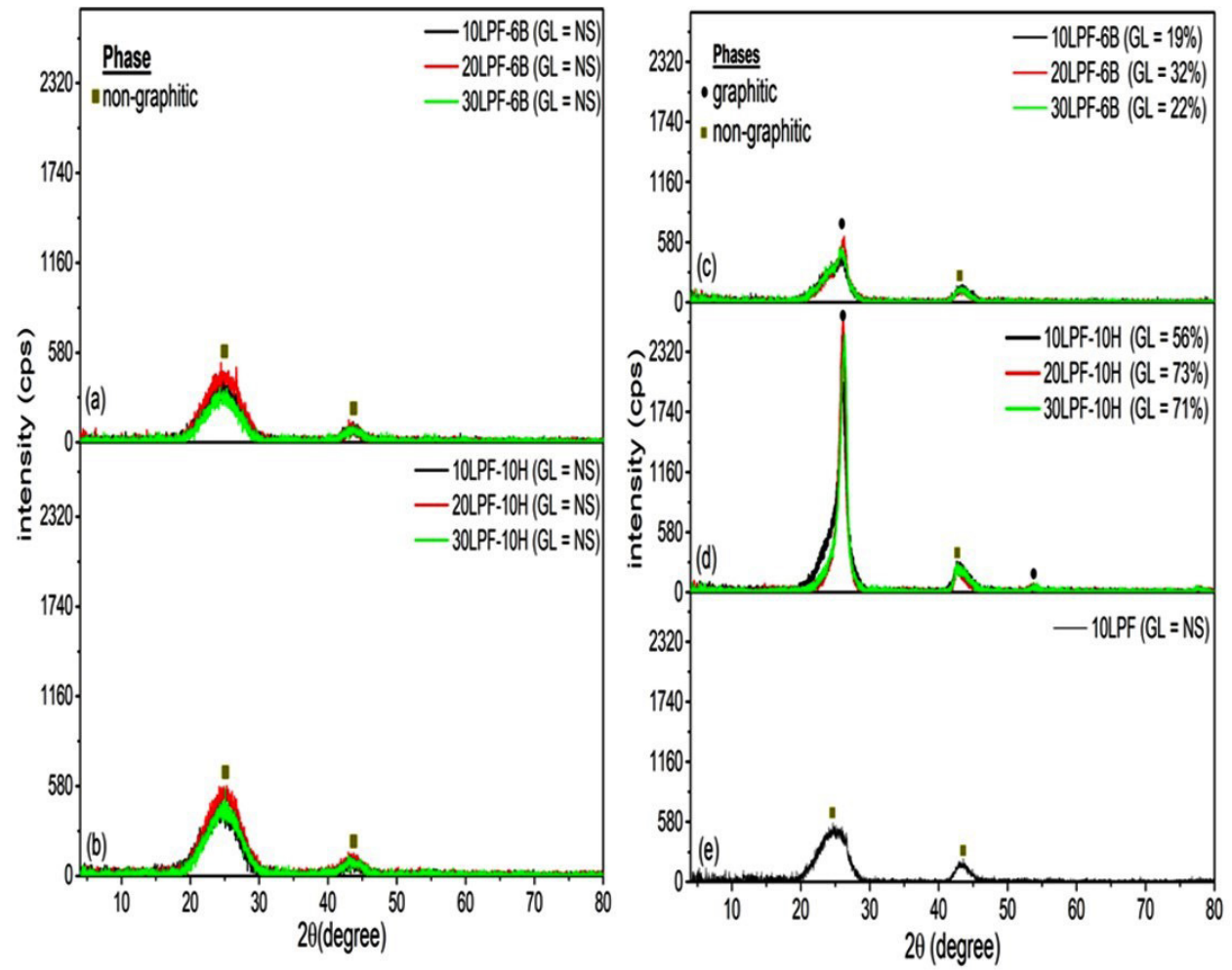

Figure 5. XRD profiles of carbons derived from lignin-phenol-formaldehyde resins containing boron compounds after pyrolysis at: (a-b) $1000{ }^{\circ} \mathrm{C}$ and $(\mathrm{c}-\mathrm{e}) 1500{ }^{\circ} \mathrm{C}$ for 5 hours. $\mathrm{LPF}=$ lignin-phenol-formaldehyde resin, $6 \mathrm{~B}=6 \mathrm{wt} . \%$ boron oxide, $10 \mathrm{H}=10 \mathrm{wt} . \%$ boric acid, $\mathrm{NS}=$ not significant.

stage, the XRD pattern revealed the presence of graphitic carbons (Figures $5 \mathrm{c}$ and $5 \mathrm{~d}$ ). The asymmetric peak at $26^{\circ}$ is due to graphene layer stacking. The results show that temperature is a critical factor in the catalytic graphitization of lignin-phenol-formaldehyde resins by the boron source additives. The higher temperature appears to provide enough energy for the carbon crystallization. The highest amount of crystalline carbons was generated in the resin formulation containing boric acid (up to $73 \%$ for $20 \mathrm{LPF}-10 \mathrm{H}$ ).

Generally, carbon atoms ordered arrangement should occur when sufficient number of bonds are broken during thermal treatment since graphite's standard formation enthalpy is $0 \mathrm{~kJ} / \mathrm{mol}^{28}$. However, the strong $\mathrm{C}-\mathrm{C}$ cross-linking during carbonization of the pristine lignin modified phenolic resin appears to prevent fusion or significant atoms movement that hinders the crystallization of the resulting carbon from the plain LPF resoles. Consequently, the mechanism for phenolic resin carbon graphitization by boron compounds can be attributed to the formation and presence of B-O-C bonds ${ }^{28,33}$. This bond has a lower binding energy $(\sim 192.2 \mathrm{eV})$ than the plain C-C $(\sim 284.7 \mathrm{eV})$, which facilitated the needed rotation for graphitic carbon generation at $1500^{\circ} \mathrm{C}$. Moreover, increased heating (up to $1500^{\circ} \mathrm{C}$ and 5 hours of dwell time) did not lead to ordered atomic arrangement of carbon derived from the plain LPF resole (Figue 5e).

The interlayer spacing $\left(\mathrm{d}_{002}\right)$ and crystallite height $\left(\mathrm{L}_{\mathrm{c}}\right)$ of the carbon samples from boron compounds modified LPF resins were calculated and the results are presented in Table 5 . The $\mathrm{d}_{002}$ values of the sample fired at $1500^{\circ} \mathrm{C} / 5 \mathrm{~h}$ are closer to that of graphite, which is $0.3354 \mathrm{~nm}$. Boron incorporation via substitution can lead to increased orderliness by disrupting the carbon atom (intercalation) or creating a more attractive force between the $\pi$-electron cloud ${ }^{28}$. Consequently, the introduction of boron can make the graphene layers to come together leading to reduced interlayer spacing. Similarly, the crystallite height of the samples carbonized up to $1500^{\circ} \mathrm{C}$ increased significantly. At this instance, graphite growth was more pronounced in the c-direction.

The TEM image of 20LPF-10H carbon derived after carbonization at $1500{ }^{\circ} \mathrm{C}$ revealed partly rod-like and onion-like graphitic structure (Figure 6a) in the diameter range of 50 to $120 \mathrm{~nm}$. This type of pattern has been observed in 
Table 5. Interlayer spacing, and crystallite height values of carbon derived from plain LPF resins containing boron compounds after firing at $1000^{\circ} \mathrm{C}$ or $1500^{\circ} \mathrm{C} / 5 \mathrm{~h}$.

\begin{tabular}{|c|c|c|c|}
\hline Samples & $\mathrm{d}_{002}(\mathrm{~nm})$ & $\mathrm{L}_{\mathrm{c}(002)}(\mathrm{nm})$ & GL \\
\hline \multicolumn{4}{|c|}{$1000^{\circ} \mathrm{C}$} \\
\hline 10LPF-6B & 0.3627 & 1.37 & $\mathrm{NS}$ \\
\hline 20LPF-6B & 0.3601 & 1.34 & $\mathrm{NS}$ \\
\hline 30LPF-6B & 0.3617 & 1.41 & NS \\
\hline 10LPF-10H & 0.3651 & 1.33 & NS \\
\hline 20LPF-10H & 0.3593 & 1.36 & NS \\
\hline $30 \mathrm{LPF}-10 \mathrm{H}$ & 0.3587 & 1.38 & NS \\
\hline \multicolumn{4}{|c|}{$1500^{\circ} \mathrm{C}$} \\
\hline 10LPF-6B & 0.3413 & 5.94 & 19 \\
\hline 20LPF-6B & 0.3402 & 7.22 & 32 \\
\hline 30LPF-6B & 0.3417 & 5.82 & 22 \\
\hline 10LPF-10H & 0.3415 & 7.84 & 46 \\
\hline 20LPF-10H & 0.3393 & 9.10 & 74 \\
\hline 30LPF-10H & 0.3394 & 8.63 & 71 \\
\hline
\end{tabular}

*NS $=$ not significant
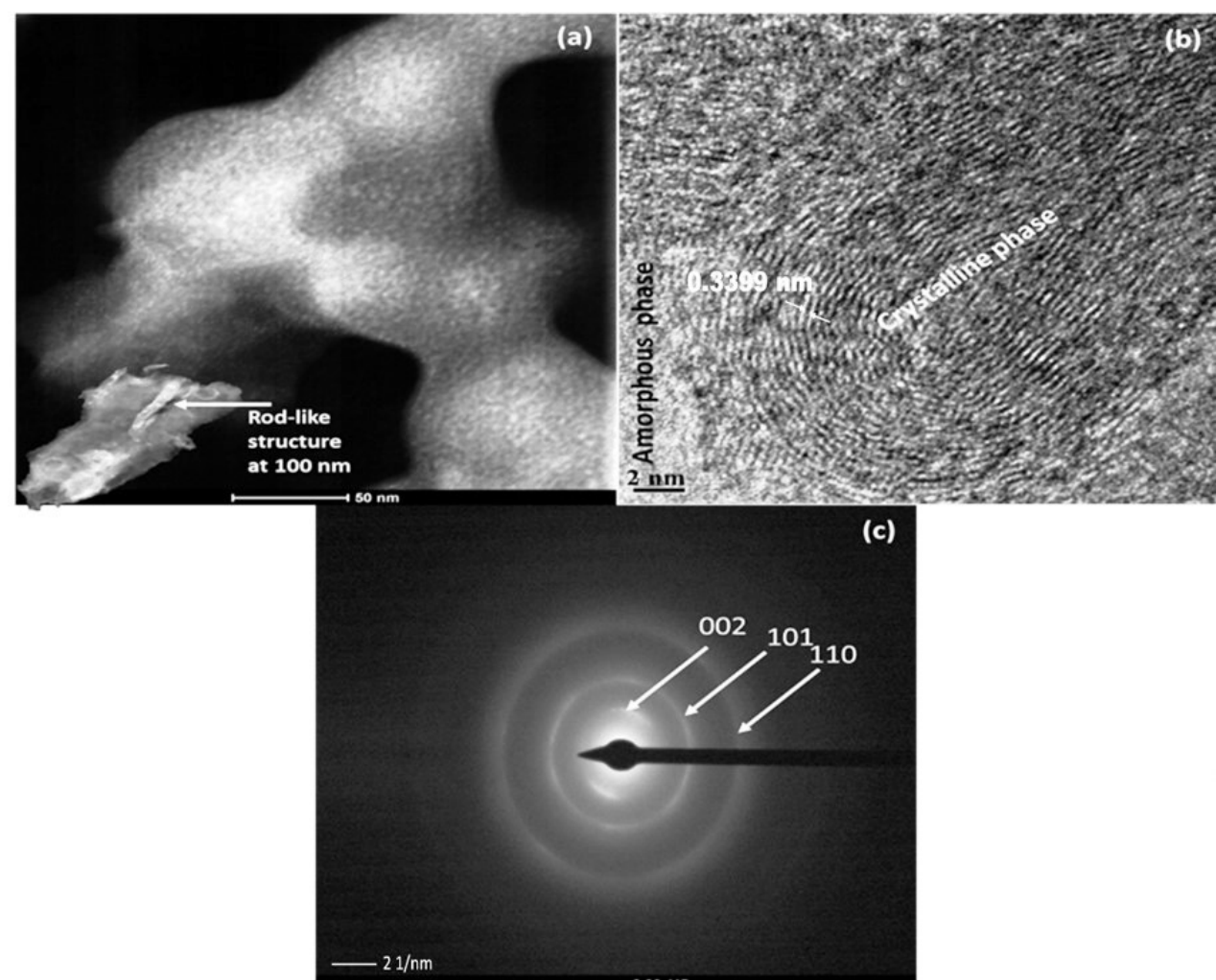

Figure 6. (a) TEM, (b) HRTEM and (c) SAED images of 20LPF-10H carbon sample prepared using sequential heat treatment process up to $1500^{\circ} \mathrm{C}$.

boron-containing graphitic carbons ${ }^{51,52}$ and is also peculiar to catalytically induced graphitization process ${ }^{53}$. The HRTEM image (Figure $6 \mathrm{~b}$ ) shows the presence of fringes and regions indicating disordered atomic arrangement, which agrees with the XRD results. The image also revealed lattice lines and amorphous regions, pointing out that $20 \mathrm{LPF}-10 \mathrm{H}$ sample is partly crystalline. The high-resolution image further attests to the presence of onion-like structure in the carbon composition. The selected area electron diffraction (SAED) pattern matches well with the HRTEM image and shows similar features of polycrystalline material with no preferred stacking orientations and short-range order. The crystal parameters estimated from the diffraction rings are 0.342 , 0.208 and $0.129 \mathrm{~nm}$ (Figure 6c). These values are close to the $\mathrm{d}_{002}, \mathrm{~d}_{101}$ and $\mathrm{d}_{110}$ planes of graphite ${ }^{54}$. The appearance of the diffraction pattern belonging to 002,101 and 110 planes is another confirmation of graphitic carbon generation from carbonized LPF resin due to the addition of boric acid. 
Furthermore, ferrocene was used to induce graphitic carbon generation during pyrolysis (stepwise heating procedure suitable for CCRs sintering) of LPF resins (10LPF, 20LPF and 30LPF). Some little amount of crystalline carbon was detected after carbonizing at $1000{ }^{\circ} \mathrm{C}$ for five hours. At that temperature, the carbon samples diffractograms were characterized with peaks at $101\left(44.8^{\circ}\right), 102\left(50.8^{\circ}\right)$, and $004\left(54^{\circ}\right)$ reflections corresponding to graphite phase (Figures 7a-7c). Nevertheless, the graphene layer stacking at the 002 plane remains broad near $26^{\circ}$. The graphitization level of the carbon samples thermally heated at $1000^{\circ} \mathrm{C}$ was presented in Table 6 . Another peak belonging to 102 plane of $\mathrm{Fe}_{3} \mathrm{Cphase}^{55}$ (which may be due to ferrocene decomposition ${ }^{56}$ ) was also detected at $43.7^{\circ}$.

Based on the attained results, the formulations containing 5 wt. $\%$ ferrocene were heated up to $1500{ }^{\circ} \mathrm{C}$ for 5 hours. The resulting carbons' diffractograms (including that of the plain resin carbon) were presented in Figures $7 \mathrm{~d}-7 \mathrm{~g}$. The amount of generated graphitic carbon in the ferrocene-containing samples significantly increased whereas the LPF resin carbon still retained its amorphous characteristic. Also, the peak attributed to the 102 plane of $\mathrm{Fe}_{3} \mathrm{C}$ substantially diminishes, whereas the one belonging to the 101 graphite plane $\left(44.8^{\circ}\right)$ increased at that higher temperature. Thus, $\mathrm{Fe}_{3} \mathrm{C}$ may have acted as sites for graphite-like carbon generation ${ }^{32}$. Consequently, the mechanism leading to the catalytic graphitization of LPF containing ferrocene composition should involve a dissolution-precipitation reaction in which graphitic carbon crystallizes from the iron carbide phase during thermal treatment. Similarly, the peak at $26^{\circ}$, which belongs to the 002 plane of graphite was detected after carbonizing at $1500{ }^{\circ} \mathrm{C}$ for 5 hours. The results, as expected, show that increased heating temperature favours the graphitization degree of LPF-Fc formulations as highlighted by GL values of the different samples shown in Table 6.

Moreover, the interlayer spacing $\left(\mathrm{d}_{002}\right)$, crystallite height $\left(\mathrm{L}_{\mathrm{c}}\right)$ and crystallite size $\left(\mathrm{L}_{\mathrm{a}}\right)$ of the carbon samples

Table 6. Interlayer spacing, and crystallite height values of carbon derived from LPF resins containing ferrocene

\begin{tabular}{ccccc}
\hline Samples & $\mathrm{d}_{002}(\mathrm{~nm})$ & $\mathrm{L}_{\mathrm{c}(002)}(\mathrm{nm})$ & $\mathrm{L}_{\mathrm{a}(101)}(\mathrm{nm})$ & $\mathrm{GL}(\%)$ \\
\hline 10LPF & 0.3690 & 1.19 & - & $\mathrm{NS}$ \\
\hline 20LPF & 0.3700 & 1.17 & - & $\mathrm{NS}$ \\
\hline 30LPF & 0.3701 & 1.19 & - & $\mathrm{NS}$ \\
\hline 10LPF-3Fc & 0.3671 & 1.18 & 13.71 & 8 \\
\hline 10LPF-4Fc & 0.3711 & 1.20 & 13.76 & 9 \\
\hline 10LPF-5Fc & 0.3689 & 1.32 & 20.45 & 13 \\
\hline 20LPF-3Fc & 0.3733 & 1.27 & 15.77 & 6 \\
\hline 20LPF-4Fc & 0.3690 & 1.14 & 12.54 & 10 \\
\hline 20LPF-5Fc & 0.3686 & 1.20 & 12.54 & 9 \\
\hline 30LPF-3Fc & 0.3678 & 1.22 & 16.41 & 15 \\
\hline 30LPF-4Fc & 0.3657 & 1.20 & 13.49 & 12 \\
\hline 30LPF-5Fc & 0.3721 & 1.17 & 13.17 & 12 \\
\hline & & $\mathbf{1 5 0 0} \mathbf{C}$ & & 41 \\
\hline 10LPF & 0.3605 & 2.13 & - & - \\
\hline 10LPF-5Fc & 0.3380 & 7.98 & 24.18 & 48 \\
\hline 20LPF-5Fc & 0.3398 & 7.28 & 31.02 & 44 \\
\hline 30LPF-5Fc & 0.3390 & 7.23 & 30.04 & 41 \\
\hline *NS = not significant & & & \\
\hline
\end{tabular}
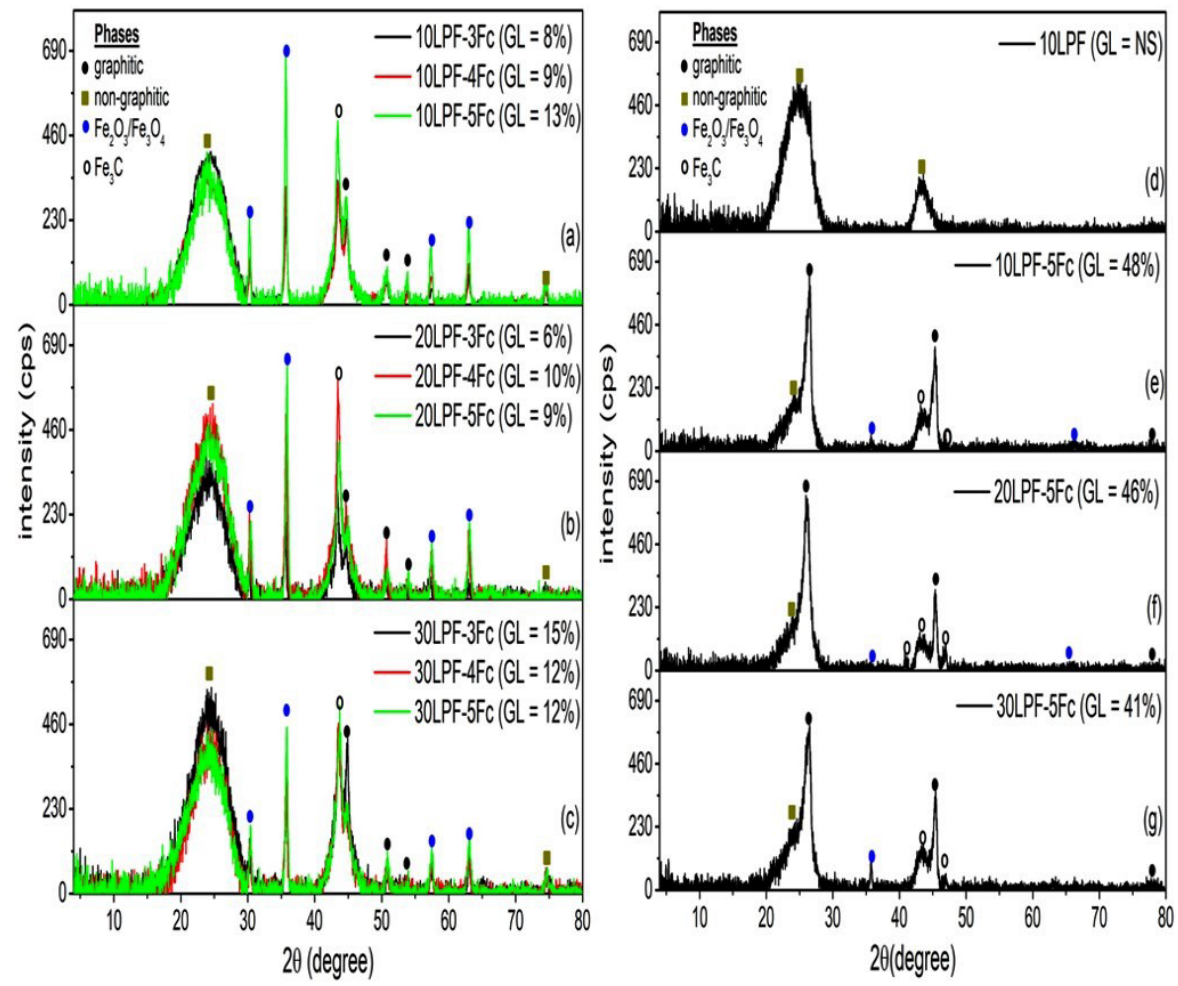

Figure 7. XRD profiles of carbons derived from lignin-phenol-formaldehyde resins containing ferrocene after pyrolysis at (a-c) $1000^{\circ} \mathrm{C}$, (d-g) $1500^{\circ} \mathrm{C}$ for 5 hours. NS = not significant. 
were determined based on the 002 plane (interlayer spacing and crystallite height) and 101 one (crystallite size) using Scherer's and Bragg's equation ${ }^{57,58}$. The results are presented in Table 6. As mentioned earlier, the decrease in $\mathrm{d}_{002}$ value and an increase in those of $\mathrm{L}_{c}$ and $\mathrm{L}_{\mathrm{a}}$ are related to higher graphitization degree after pyrolysis at $1500{ }^{\circ} \mathrm{C}$ for 5 hours. Under these conditions, crystallization was also observed along the a-direction (unlike with boron compound resin formulations) based on the XRD results.

Figure 8 a shows the TEM image of 20LPF-5Fc carbon with a cage-like graphitic domain, which is peculiar to partially graphitized carbon that is mainly associated with the 002 plane ${ }^{59}$. Another phase corresponding to iron oxide ( $\mathrm{Fe}=88$ wt.\%, $\mathrm{O}=12$ wt. $\%$ ) was detected in the carbon composition. The corresponding HRTEM image also revealed distinct fringes corresponding to 002 lattice plane with an average interlayer spacing value of $0.342 \mathrm{~nm}$ (Figure 8b). Regarding the SAED measurement (Figure 8c), the individual spots which represent the lattice plane distance corresponding to $\mathrm{d}_{002}$ of graphitic carbon and Fe crystals were observed on the pattern. However, the diffraction rings were barely visible.

\subsection{Oxidation resistance of the carbon samples prepared from the resin formulations containing boric acid, boron oxide and ferrocene}

The oxidation resistance of carbons derived from the LPF resins (10LPF, 20LPF, 30LPF) containing ferrocene, boron oxide or boric acid was determined. The resulting thermogravimetric profiles after heating the samples in a non-reducing atmosphere are shown in Figure 9. The actual carbon loss values, which were calculated as described in Section 2.7 are presented in Table 7. Firstly, a direct correlation was not established between the samples' oxidation resistance and the attained graphitization level. However, the carbons derived from the resin formulations containing boron-oxide presented the least carbon loss, irrespective of the resin type, i.e. $10 \mathrm{LPF}, 20 \mathrm{LPF}$ or $30 \mathrm{LPF}$. $30 \mathrm{LPF}$ formulation containing $6 \mathrm{wt} . \%$ boron oxide presented the least amount of carbon at temperatures up to $1000{ }^{\circ} \mathrm{C}$ in an oxidizing environment. Based on a previous study ${ }^{33}$, this observation was attributed to the presence of boron oxide, which can form a protective oxide coating on the carbon

Table 7. Oxidation resistance of carbons derived the lignin-phenol-formaldehyde resins.

\begin{tabular}{|c|c|c|c|c|c|}
\hline & \multicolumn{2}{|c|}{ Reference } & $6 \mathrm{wt} \% \%$ B & 10 wt. $\% \mathrm{H}$ & 5 wt. $\%$ Fc \\
\hline Carbon loss (\%) & $10 \mathrm{LPF}$ & 48 & 46.5 & 54.3 & 46.9 \\
\hline $\mathrm{T}_{\mathrm{i}}\left({ }^{\circ} \mathrm{C}\right)$ & & 632 & 606 & 600 & 612 \\
\hline Carbon loss (\%) & $20 \mathrm{LPF}$ & 46.0 & 44.2 & 47.1 & 54.6 \\
\hline $\mathrm{T}_{\mathrm{i}}\left({ }^{\circ} \mathrm{C}\right)$ & & 610 & 606 & 593 & 594 \\
\hline Carbon loss (\%) & $30 \mathrm{LPF}$ & 46.0 & 38.5 & 57.9 & 63.2 \\
\hline $\mathrm{T}_{\mathrm{i}}\left({ }^{\circ} \mathrm{C}\right)$ & & 619 & 595 & 603 & 617 \\
\hline
\end{tabular}

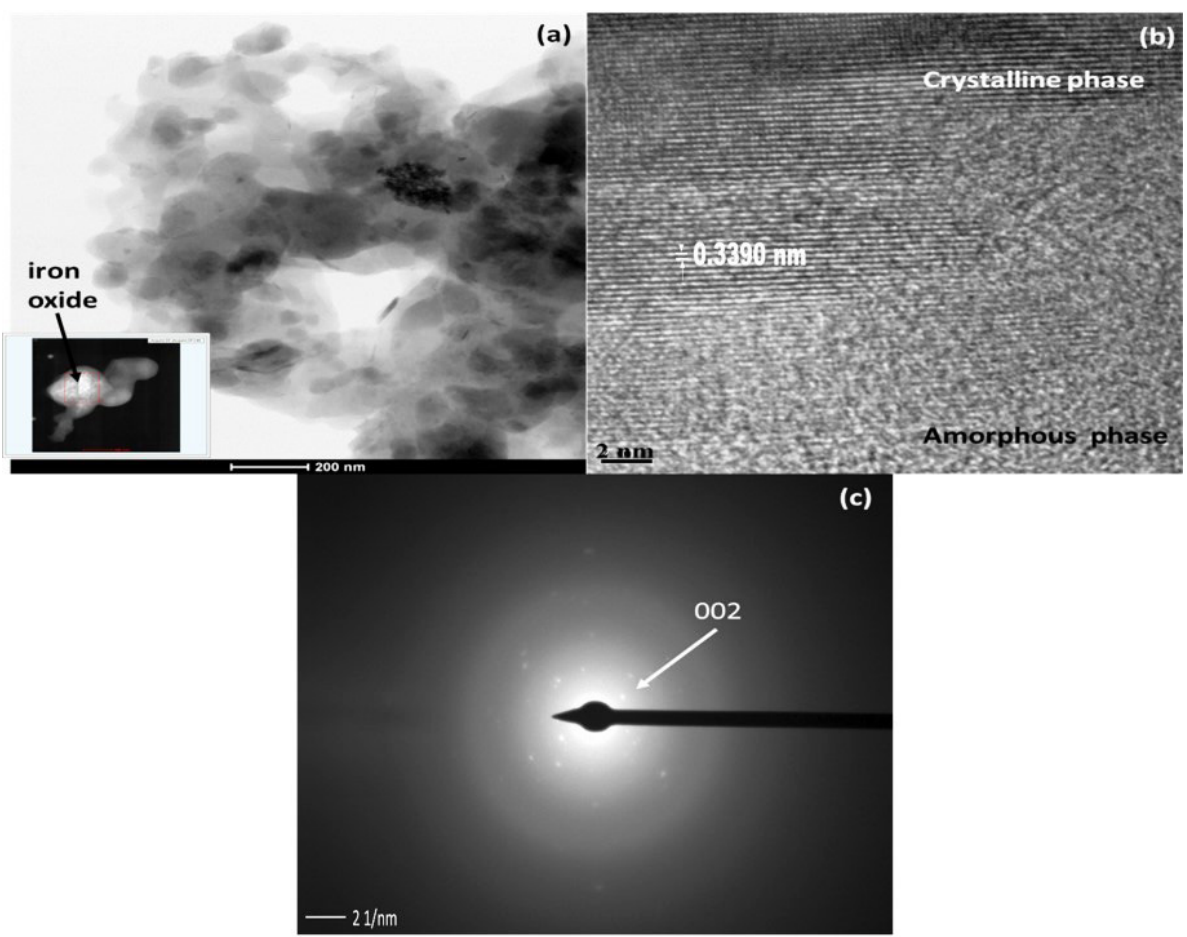

Figure 8. (a) TEM, (b) HRTEM and (c) SAED images of 20LPF-5Fc carbon sample prepared using sequential heat treatment process up to $1500^{\circ} \mathrm{C}$ for 5 hours. 


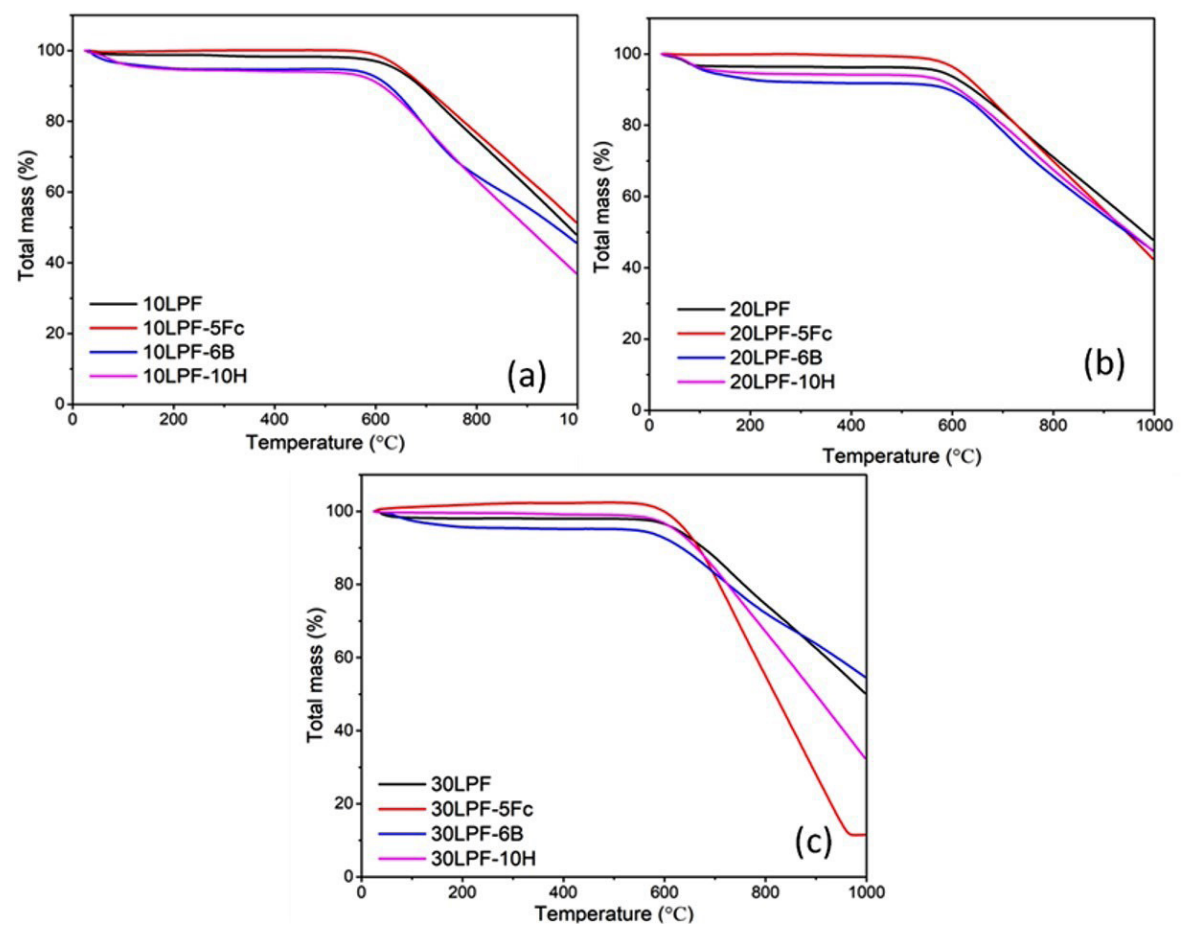

Figure 9. TG curves of carbon samples derived from plain LPF resin and the ones containing boron oxide, boric acid and ferrocene (a) 10LPF, (b)20LPF and (c) 30LPF, synthesized with $10 \mathrm{wt} . \%, 20 \mathrm{wt} . \%$ and $30 \mathrm{wt} . \% \mathrm{kraft}$ lignin, respectively.

surface thereby reducing oxidation rate. Nevertheless, $10 \mathrm{LPF}-5 \mathrm{Fc}$ and $20 \mathrm{LPF}-10 \mathrm{H}$ may be the most suitable binder formulations for CCRs production due to the combined effect of their carbons' crystallinity (GL $=48 \%$ and $73 \%$, respectively) and thermal stability in air.

As observed in previous results ${ }^{32,33,60}$, carbon oxidation resistance usually depends on a combination of factors such as chemical composition, atoms arrangement, bond strength and the direction of oxidation reaction (i.e., across the crystallographic or basal plane). These parameters influence the material high-temperature oxidization behaviour. Consequently, it was difficult to isolate the effect of crystallization on reactivity during the thermogravimetric measurement of such samples. More so, unlike pure graphite in which oxidation occurs along a well-defined crystallographic path, the process is more dominant in the c-direction for pyrolytic carbons. Therefore, for amorphous carbon such as those obtained from LPF resins, the atoms cross-linking degree appears to play a significant role on the samples thermal stability in an oxidizing environment due to strong covalent bond ${ }^{61,62}$. This observation is evident in the higher oxidation initiation temperature $\left(\mathrm{T}_{\mathrm{i}}\right)$ values of $10 \mathrm{LPF}, 20 \mathrm{LPF}$ and $30 \mathrm{LPF}$ carbon samples (Table 7).

\section{Conclusions}

LPF resins were synthesized using thermally treated kraft lignin that is rich in $\mathrm{OH}$ group and characterized with syringyl and guaiacyl unit in its chemical structure. The heat treatment led to the cleavage of ether linkages, reduced molecular weight and polydispersivity, which induced better reactivity and easier synthesis. The ortho-substituted links increased proportionally with the quantity of used lignin especially for 30LPF resin, which was developed with 30 wt. $\%$ substituted phenol. After carbonization, the carbons derived from the LPF resins have an amorphous-like structure, which can limit the thermomechanical and chemical performance of CCRs. However, ferrocene, boron oxide and boric acid addition to the lignin-phenol-formaldehyde resins led to graphitic carbon generation during their thermal treatment. The highest graphitization level (73\%) was attained when 20LPF resin containing $10 \mathrm{wt} . \%$ boric acid was pyrolyzed using sequential heating sequence up to $1500^{\circ} \mathrm{C}$ for 5 hours. The microstructural images provided supporting information that attests to the resulting carbons crystallization. However, a definite relationship was not established between the attained oxidation resistance of the samples and their graphitization level. More so, the less expensive boric acid acts as a better graphitizing agent compared to ferrocene. Finally, LPF resins appear to have a good prospect as a binder in the preparation of resin bonded carbon-containing bricks, considering the aspect of production cost and possible graphitization of their carbons.

\section{Acknowledgements}

This research was supported by a $\mathrm{PhD}$ scholarship from TWAS/CNPq (190109/2015-7). The authors acknowledged the contributions of FIRE-Omega project, INCT/MIDAs, FIBRIA, RHI-MAGNESITA, PPGCEM-UFSCAR for providing some of the materials and facilities used for this research. Besides, this study was financed in part by the Coordenação de Aperfeiçoamento de Pessoal de Nível Superior - Brasil (CAPES) - Finance Code 001. 


\section{References}

1. Alonso MV, Oliet M, Rodríguez F, García J, Gilarranz MA, Rodríguez JJ. Modification of ammonium lignosulfonate by phenolation for use in phenolic resins. Bioresour Technol. 2005;96(9):1013-8.

2. Lihong HP, Zhou Y, Zhang M. Method to improve lignin's reactivity as a phenol substitute and a replacement for other phenolic compounds: a brief review. BioResources. 2011;6(3):3515-25.

3. Gardziella A, Pilato LA, Knop A. Phenolic resins: chemistry, applications, standardization, safety and ecology. 2 ed. New York: Springer-Verlag Berlin Heidelberg; 2000.

4. Gellerstedt G, Henriksson G. Chapter 9 - Lignins: Major Sources, Structure and Properties - Belgacem, Mohamed Naceur. In: Gandini A, editor. Monomers, Polymers and Composites from Renewable Resources. Amsterdam: Elsevier; 2008. p. 201-224.

5. Sarkar S, Adhikari B. Lignin-modified phenolic resin: synthesis optimization, adhesive strength, and thermal stability. J Adhes Sci Technol. 2000;14(9):1179-93.

6. Klapiszewski L, Jamrozik A, Strzemiecka B, Matykiewicz D, Voelkel A, Jesionowski T. Activation of magnesium lignosulfonate and kraft lignin: influence on the properties of phenolic resin-based composites for potential applications in abrasive materials. International Journal of Molecular Sciences. 2017;18(6): 1224.

7. Xu C, Ferdosian F. Lignin-Based Phenol-Formaldehyde (LPF) resins/adhesives. Conversion of lignin into bio-based chemicals and materials. Berlin, Heidelberg: Springer Berlin Heidelberg; 2017. p. 91-109.

8. Tejado A, Kortaberria G, Labidi J, Echeverria JM, Mondragon I. Isoconversional kinetic analysis of novolac-type lignophenolic resins cure. Thermochim Acta. 2008;471(1):80-5.

9. Matsushita Y, Wada S, Fukushima K, Yasuda S. Surface characteristics of phenol-formaldehyde-lignin resin determined by contact angle measurement and inverse gas chromatography. Ind Crops Prod. 2006;23(2):115-21.

10. Ma Y, Zhao X, Chen X, Wang Z. An approach to improve the application of acid-insoluble lignin from rice hull in phenolformaldehyde resin. Colloids Surf A Physicochem Eng Asp. 2011;377(1):284-9.

11. Olivares M, Guzmán JA, Natho A, Saavedra A. Kraft lignin utilization in adhesives. Wood Sci Technol. 1988;22(2):157-65.

12. Donmez Cavdar A, Kalaycioglu H, Hiziroglu S. Some of the properties of oriented strandboard manufactured using kraft lignin phenolic resin. J Mater Process Technol. 2008;202(1):559-63.

13. Danielson B, Simonson R. Kraft lignin in phenol formaldehyde resin. Part 1. Partial replacement of phenol by kraft lignin in phenol formaldehyde adhesives for plywood. J Adhes Sci Technol. 1998;12(9):923-39.

14. Qiao W, Li S, Guo G, Han S, Ren S, Ma Y. Synthesis and characterization of phenol-formaldehyde resin using enzymatic hydrolysis lignin. J Ind Eng Chem. 2015;21:1417-22.

15. Jin Y, Cheng X, Zheng Z. Preparation and characterization of phenol-formaldehyde adhesives modified with enzymatic hydrolysis lignin. Bioresour Technol. 2010;101(6):2046-8.

16. Jing Z, Lihong H, Bingchuan L, Caiying B, Puyou J, Yonghong Z. Preparation and characterization of novolac phenol-formaldehyde resins with enzymatic hydrolysis lignin. Journal of the Taiwan Institute of Chemical Engineers. 2015;54:178-82.

17. Nada AMN, Abou-Youssef H, El-Gohary SEM. Phenol Formaldehyde Resin Modification with Lignin. Polym Plast Technol Eng. 2003;42(4):689-99.

18. Zhang W, Ma Y, Wang C, Li S, Zhang M, Chu F. Preparation and properties of lignin-phenol-formaldehyde resins based on different biorefinery residues of agricultural biomass. Ind Crops Prod. 2013;43:326-33.
19. Zhang W, Ma Y, Xu Y, Wang C, Chu F. Lignocellulosic ethanol residue-based lignin-phenol-formaldehyde resin adhesive. Int J Adhes Adhes. 2013;40:11-8.

20. Kalami S, Arefmanesh M, Master E, Nejad M. Replacing 100\% of phenol in phenolic adhesive formulations with lignin. Journal of Applied Polymer Science. 2017;134(30):45124.

21. $\mathrm{Hu}$ TQ. Chemical modification, properties, and usage of lignin. USA: Springer; 2002.

22. Cheng S, Yuan Z, Leitch M, Anderson M, Xu C. Highly efficient de-polymerization of organosolv lignin using a catalytic hydrothermal process and production of phenolic resins/adhesives with the depolymerized lignin as a substitute for phenol at a high substitution ratio. Ind Crops Prod. 2013;44:315-22.

23. Siddiqui H, Mahmood N, Yuan Z, Crapulli F, Dessbesell L, Rizkalla A, et al. Sustainable bio-based phenol-formaldehyde resoles using hydrolytically depolymerized kraft lignin. Molecules (Basel, Switzerland). 2017;22(11):1850.

24. Ohra-aho T, Gomes FJB, Colodette JL, Tamminen T. S/G ratio and lignin structure among Eucalyptus hybrids determined by Py-GC/MS and nitrobenzene oxidation. J Anal Appl Pyrolysis. 2013;101:166-71.

25. Min D, Xiang Z, Liu J, Jameel H, Chiang V, Jin Y, et al. Improved Protocol for Alkaline Nitrobenzene Oxidation of Woody and Non-Woody Biomass. J Wood Chem Technol. 2015;35(1):5261.

26. Qin Y, Yang D, Qiu X. Hydroxypropyl Sulfonated Lignin as Dye Dispersant: Effect of Average Molecular Weight. ACS Sustain Chem\& Eng. 2015;3(12):3239-44.

27. Wang F, Zhao L, Fang W, He X, Liang F, Chen H, et al. Preparation of Organic/Inorganic Composite Phenolic Resin and Application in $\mathrm{Al}_{2} \mathrm{O}_{3}-\mathrm{C}$ Refractories. Int $\mathrm{J}$ Appl Ceram Technol. 2016;13(1):133-9.

28. Talabi SI, Luz AP, Lucas AA, Pagliosa C, Pandolfelli VC. Catalytic graphitization of novolac resin for refractory applications. Ceram Int. 2018;44(4):3816-24.

29. Bitencourt CS, Luz AP, Pagliosa C, Pandolfelli VC. Role of catalytic agents and processing parameters in the graphitization process of a carbon-based refractory binder. Ceram Int. 2015;41(Suppl 10, Pt A):13320-1330.

30. Jansen $\mathrm{H}$. Bonding of $\mathrm{MgO}-\mathrm{C}$ bricks by catalytically activated resin. London: Millennium Steel Int.; 2007. p. 95-98.

31. Bartha P, Jansen H, Daldrup HG. Carbonaceous refractory shaped body with improved oxidation behavior and batch composition and method for producing the same. USA: Google Patents; 2005.

32. Talabi SI, Luz AP, Pandolfelli VC, Bernardes JS, Lucas AA. Synthesis and graphitization of resole resins by ferrocene. Progress in Natural Science: Materials International. 2019;26:71-80.

33. Talabi SI, Luz AP, Pandolfelli VC, Lucas AA. Structural evolution during the catalytic graphitization of a thermosetting refractory binder and oxidation resistance of the derived carbons. Mater Chem Phys. 2018;212:113-21.

34. Li J, Wang W, Zhang S, Gao Q, Zhang W, Li J. Preparation and characterization of lignin demethylated at atmospheric pressure and its application in fast curing biobased phenolic resins. RSC Advances. 2016;6(71):67435-6743.

35. Watkins D, Nuruddin M, Hosur M, Tcherbi-Narteh A, Jeelani S. Extraction and characterization of lignin from different biomass resources. Journal of Materials Research and Technology. 2015;4(1):26-32.

36. Boeriu CG, Bravo D, Gosselink RJA, van Dam JEG. Characterisation of structure-dependent functional properties of lignin with infrared spectroscopy. Ind Crops Prod. 2004;20(2):205-18.

37. Santos JI, Martín-Sampedro R, Fillat U, Oliva JM, Negro MJ, Ballesteros M, et al. Evaluating lignin-rich residues from biochemical ethanol production of wheat straw and olive tree pruning by FTIR and 2D-NMR. Int J Polym Sci. 2015;2015:111. 
38. Kline LM, Hayes DG, Womac AR, Labbe N. Simplified determination of lignin content in hard and soft woods via uv-spectrophotometric analysis of biomass dissolved in ionic liquids. BioResources. 2010;(5):1366-83.

39. Durie R, Lynch B, Sternhell S. Comparative studies of brown coal and lignin. i. infra-red spectra. Aust J Chem. 1960;13(1):156-68.

40. Briggs LH, Colebrook LD, Fales HM, Wildman WC. Infrared absorption spectra of methylenedioxy and aryl ether groups. Anal Chem. 1957;29(6):904-11.

41. Hergert HL. Infrared spectra of lignin and related compounds. II. Conifer lignin and model compounds. J Org Chem. 1960;25(3):405-13.

42. Lv P, Almeida G, Perré P. TGA-FTIR analysis of torrefaction of lignocellulosic components (cellulose, xylan, lignin) in isothermal conditions over a wide range of time durations. BioResources. 2015;(10):4239-51.

43. Byko VI. Characterization of natural and technical lignins using FTIR spectroscopy. Suecia: Lulea University of Technology; 2008. p. 43

44. Zhang X, Yan Q, Leng W, Li J, Zhang J, Cai Z, et al. Carbon nanostructure of Kraft lignin thermally treated at 500 to $1000^{\circ} \mathrm{C}$. Materials. 2017;10(8):975.

45. Kawamoto H. Lignin pyrolysis reactions. J Wood Sci. 2017;63(2):117-32

46. Nakamura T, Kawamoto H, Saka S. Pyrolysis behavior of Japanese cedar wood lignin studied with various model dimers. J Anal Appl Pyrolysis. 2008;81(2):173-82.

47. Domínguez JC, Oliet M, Alonso MV, Rojo E, Rodríguez F. Structural, thermal and rheological behavior of a bio-based phenolic resin in relation to a commercial resol resin. Ind Crops Prod. 2013;42:308-14.

48. Tejado A, Peña C, Labidi J, Echeverria JM, Mondragon I. Physico-chemical characterization of lignins from different sources for use in phenol-formaldehyde resin synthesis. Bioresour Technol. 2007;98(8):1655-63.

49. Ida Poljanšek MK. Characterization of phenol-formaldehyde prepolymer resins by in line FT-IR spectroscopy. Acta Chim Slov. 2005;52(3):238-44.

50. Wang S, Wang Y, Bian C, Zhong Y, Jing X. The thermal stability and pyrolysis mechanism of boron-containing phenolic resins: the effect of phenyl borates on the char formation. Appl Surf Sci. 2015;331:519-29.

51. Sato Y, Nishizaka H, Motomiya K, Yamamoto G, Okubo A, Kimura $\mathrm{H}$, et al. Boron-assisted transformation to rod-like graphitic carbons from multi-walled carbon nanotubes in boron-mixed multi-walled carbon nanotube solids. ACS Appl Mater Interfaces. 2011;3(7):2431-9.

52. Kim JS, Kim SJ, Kim GH, Chun CH, Koou HH. Characterization of boron containing graphite using TEM and EELS. Microsc Microanal. 2002;8(S02):610-1.

53. Cabioc'h T, Thune E, Jaouen M. Mechanisms involved in the formation of onionlike carbon nanostructures synthesized by ion implantation at high temperature. Physical Review B. 2002;65(13): 132103 .

54. Dutta NJ, Mohanty SR, Buzarbaruah N. Modification on graphite due to helium ion irradiation. Phys Lett A. 2016;380(33):252530.

55. Qin H, Huang Y, Liu S, Fang Y, Li X, Kang S. Synthesis and properties of magnetic carbon nanocages particles for dye removal. J Nanomater. 2015;2015:1-8.

56. Stamatin I, Morozan A, Dumitru A, Ciupina V, Prodan G, Niewolski J, et al. The synthesis of multi-walled carbon nanotubes (MWNTs) by catalytic pyrolysis of the phenol-formaldehyde resins. Physica E. 2007;37(1-2):44-8

57. Beatty RL. Graphitization kinetics of fluidized-bed pyrolytic carbons. Tennessee: Oak Ridge National Laboratory; 1974.

58. Vázquez-Santos MB, Geissler E, László K, Rouzaud J-N, Martínez-Alonso A, Tascón JMD. Comparative XRD, Raman, and TEM study on graphitization of PBO-derived carbon fibers. J Phys Chem C. 2012;116(1):257-68.

59. Harris PJF. New perspectives on the structure of graphitic carbons. Crit Rev Solid State Mater Sci. 2005;30(4):235-53.

60. Ruff O. Reactions of solid carbon with gases and liquids. Trans Faraday Soc. 1938;34:1022-33.

61. Luz AP, Renda CG, Lucas AA, Bertholdo R, Aneziris CG, Pandolfelli VC. Graphitization of phenolic resins for carbonbased refractories. Ceram Int. 2017;43(11):8171-82.

62. Chang HW, Rhee SK. Oxidation of carbon derived from phenolic resin. Carbon. 1978;16(1):17-20. 